\title{
Power Flow management among PV, BESS and Grid for EV Charging
}

\author{
Er. Menaka Karki**, Dol Raj Kunwar*, Bijay Sharma*, Sunil Paudel*, Tanka Nath Ojha* \\ ** Deputy-HOD, Department of Electrical Engineering, Pashchimanchal Campus, Lamachaur, Pokhara \\ **menu11karki@gmail.com,menaka@wrc.edu.np \\ *Department of Electrical Engineering, Pashchimanchal Campus, Lamachaur, Pokhara \\ astodsk38@gmail.com
}

\begin{abstract}
Electric Vehicles (EVs) are the cleanest means of transportation compared to the conventional vehicles. Unlike conventional vehicles, EVs do not depend on petroleum products and thus use of electric vehicle is going to dominate the transportation sector soon. The battery electric vehicles need charging stations for their battery to charge. The proposed topology focuses on power flow management for charging of EV loads. it proposes electric vehicle charging system in which vehicle owners are allowed to park their vehicle in the charging station and EVs are charged up to their desired SOC level. The proposed system promotes penetration of RES to a larger extent which minimizes the kwh cost of grid energy consumption, and hence generating significant economical revenue of the charging station. In this paper, charging station is modeled with PV, battery and grid, and power management strategies are proposed among them. Regulation of load sharing and prevention of mismatch between circulating currents supplied by power sources is implemented using fixed droop method. The trend of power demand by EVs in the charging station is estimated and matching between demand and supply is implemented. Energy storage system is used in order to support continuous power availability in the station. The simulations are successfully implemented to validate the effectiveness of the system and to demonstrate the load management system by the uncoordinated method of charging. The overall system is implemented by algorithm run in MATLAB/Simulink.
\end{abstract}

Keywords: Electric vehicle charging; power flow management, Droop method.

\section{Introduction}

Currently, transport sector faces significant challenges regarding the energetic model based on oil products. In fact, $65.3 \%$ of the oil consumed in the world in 2016 was due to the transport sector, which caused emissions of
$6892 \mathrm{Mt}$ of $\mathrm{CO}_{2}$ into the environment[1]. This dependence and the excessive use of oil entails numerous issues: environmental problems such as climate change and pollution in large cities, economic problems due to rising oil prices and geopolitical problems due to the instability of 
the producing countries and oil use as economic weapon. In this scenario, electric vehicles (EVs), could be a sustainable alternative to internal combustion engine vehicles. Adding much advancement and technology, the electric vehicles can be charged using solar power via photovoltaic cells (PV). So here EVs can avoid using first person. can appropriately use the combination of solar power and grid power.

The EVs draws electricity from battery from charging station in which the interconnected grid is present along with PV. Thus, many countries have been introducing the EVs as their way of transportation. But the limitations for this concept is that there is the problem of slow charging thus the time problem is quite bulky. But this can be solved with the proper scheduling.

The main objective of this paper is to manage different power sources (PV, battery and grid) in accordance with varying load demand from electric vehicle. Power flow from the sources is to be managed such that the first load sharing priority is given to the $\mathrm{PV}$ in order to utilize all the available power of the PV.

Electric vehicle can be charged with constant or variable power supply. Charging with variable power supply is less efficient. Constant power charging is necessary for EVs battery to reduce polarization. That's why charging with constant power is prominent. Reference[2] proposed the charging processes in uncoordinated and coordinated manner. In uncoordinated charging, the charging process is performed at on-board charger power rating without any control. Coordinated charging meets the expectation of both the utility operators and EV users. [3] PEVs are currently considered as simple loads due to their low market penetration. However, as the PEV fleet grows, implementation of an intelligent management system will be necessary in order to avoid large capital expenditures in network reinforcements and negative effects on electric distribution networks, such as: voltage deviations, transformers and lines saturations, increase of electrical losses, etc. These issues may jeopardize the safety and reliability of the grid. As a consequence, this topic has been researched in many papers where a wide range of solutions have been proposed. This paper presents a review of different strategies, algorithms and methods to implement a smart charging control system. Also significant projects around the world about PEVs integration are presented. Finally, on the basis of this review, main findings and some recommendations are presented. (C) 2014 Elsevier Ltd.","author":[\{"droppingparticle":" ", "family":"GarcíaVillalobos", "given": " J. ", "nond ropping-particle ": " ", "parse names":false,"suffix":""\},\{"dropping-pa rticle":" ", family":"Zamora", "given":" I. ", "non-dropping-particle":" ", "parsenames":false, "suffix":" "\}, \{"droppingparticle":"","family":"San Martín","given":"J. I.","non-dropping-particle":"","parse-names":f alse,"suffix":"" \},\{"dropping-particle":"","fam ily":"Asensio","given":"F. J.","non-droppingparticle":"","parse-names":false,"suffix":"" \}, \{ "dropping-particle":"","family":"Aperribay"," given":"V.","non-dropping-particle":"","parse- 

names":false, "suffix":" " \}], "containertitle":"Renewable and Sustainable Energy Reviews","id":"ITEM-1","issued": \{"dateparts":[["2014"]]\},"page":"717-731","publisher ":"Elsevier","title":"Plug-in electric vehicles in electric distribution networks: A review of smart charging approaches","type":"article-journal", "volume":"38"\}, "uris":["http://www.mendeley. com/documents/?uuid=7612bdd2-3d94-413aa7ef-bf545a1b17b0"]\}],"mendeley":\{"formatt edCitation":"[3]","plainTextFormattedCitation ":"[3]","previouslyFormattedCitation":"[3]" \}," properties": \{"noteIndex":0\},"schema":"https:// github.com/citation-style-language/schema/ raw/master/csl-citation.json" h had proposed smart charging, which contributes in peak shavings and valley fillings. The centralized and decentralized control strategies are also proposed as the methods of smart charging.

Grid tied PV-battery hybrid technology is proposed by[4]which may not be supported by the grid. In this paper, an optimal power flow technique of a PV-battery powered fast EV charging station is presented to continuously minimize the operation cost. The objective is to help the penetration of PV-battery systems into the grid and to support the growing need of fast EV charging. An optimization problem is formulated along with the required constraints and the operating cost function is chosen as a combination of electricity grid prices and the battery degradation cost. In the first stage of the proposed optimization procedure, an offline particle swarm optimization (PSO, which supports the reduction of the stress on the grid line due to overloads. A probabilistic model has been proposed by [5] to predict EV charging load, may not account for all possible factors that could affect the power system. Thus, a stochastic approach is applied that takes into account various realistic factors such as EV battery capacity, state of charge (SOC, which presents complete mobility patterns of EVs in order to estimate an expected load in the system to illustrate rigorous power quality index that may be used by utilities to upgrade their infrastructures supporting large penetration of EVs. Simulation and analysis of photovoltaic system with boost converter is proposed and presented by [6] where the integration of dcdc boost converter with PV is done and the voltage is made almost constant by using PID Controller. Similarly, reference [7] proposed multi-source model and developed a control algorithm for EV charging. It also presented real time monitoring of power demand and supply. To reduce stress in the grid, power demand by EV is supplied by PV and Energy storage system (Battery) by adopting an optimization algorithm, where priority wise selection of sourced is implemented. When multiple power sources are connected in parallel for supplying common load, the load sharing in dc power system is to be regulated. Reference [8] proposed current sharing control of parallel boost converters based on droop index. Droop regulation method for load sharing has been commonly used in different literatures.

This paper presents the MATLAB simulation model of power management strategy among PV, BESS and grid at different times of a day for electric vehicle charging. The proposed strategy 
is based on the uncoordinated charging method of electric vehicle in which power sources are managed for providing all the demand of EV loads. This paper focuses on to the use of RES for reducing the stress on the Grid due to high power demand from electric vehicle for charging.

\section{Modeling of components}

\section{A. Modeling of PV, BESS and Grid}

a) Photovoltaic Array: The power output from the PV depends on irradiance and temperature conditions. The model of PV array available in MATLAB is used and is operated with various values of temperature and irradiances. Number of modules connected in series and parallel determines its rating (maximum power). $\mathrm{Pv}$ array is modeled with rating such that it could provide the base load demand in the charging station, which is estimated to be $28 \mathrm{~kW}$. For providing base load, $8 \times 17 \mathrm{PV}$ pannel with the maximum output voltage and current rating of $\mathrm{PV}$ is $240 \mathrm{~V}$ and $120 \mathrm{~A}$ is used. The PV arraay is connected to the DC link via boost converter with PID control to match the voltage output of PV with DC link voltage. The another purpose of using PID controller is that it makes converter output voltage follow the reference voltage provided by load sharing algorithm.

b) Battery Energy Storage System: the Battery storage system should provide the base power demand of $28 \mathrm{~kW}$ during the peak load period. The rating of storege should be $140 \mathrm{kWh}$ for providing load continuously up to 5 hours when full charged. BESS is connected to the DC link via its boost converter along with PID controller in the same way as PV is connected. The charging and discharging of battery is controlled though a switch operated by power management algorithm.

c) Grid: Grid delivers the peak demand in case of availability of PV and storage, and supplies all load demands when base power supplying units do not have enough power. A step down three phase transformer is used to deliver the load via controlled rectifier backed by dc-dc onverter to improve power factor. $\mathrm{kVA}$ rating of transformer is to be equivalent to peak power demand from the grid. For the simulation, three phase voltage source of $240 \mathrm{~V}$ has been used as a grid.

\section{B. Modeling of EV loads}

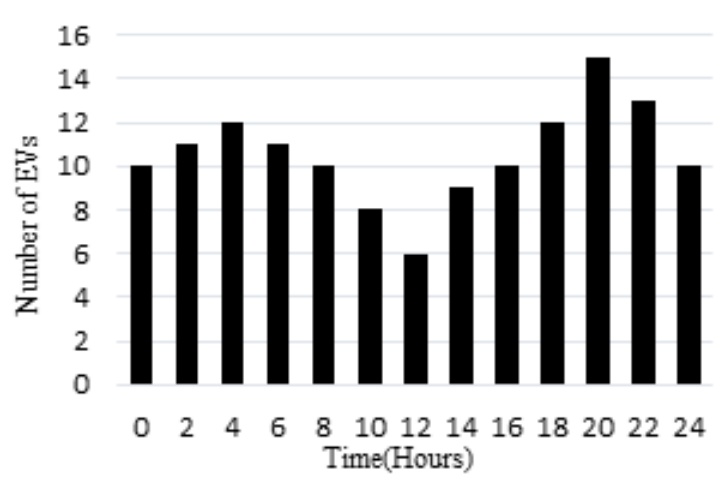

Figure II.I Number of EVs plugged in a typical day

The load demand in the charging station varies continuously and accurate load forecasting is very difficult as the load demand by the EV depends on many factors including activities and driving pattern of vehicle owner. Furthermore, instantaneous power demand depends on the numbers of simultaneous EVs plugged in a typical day is assumed to be varying as shown 
in Figure II.I.

The load modeling is based on the experiment data of a typical march day as presented in [9]. It shows the variation of number of electrical vehicles with time of a day. It shows that the EV load is maximum between 7:00pm to 9:00 pm. The station has capacity to charge up to $15 \mathrm{EVs}$ at a time. The specifications of each electric vehicles are taken from reference [10]. Here, level 2 charging of battery is used in which the $\mathrm{EV}$ is provided with $240 \mathrm{~V}$ dc input and current of 15A. Table II.I represents the specifications of the EVs.

Table II.I EV specification [10]

\begin{tabular}{|l|l|}
\hline Electric vehicle model & Nissan Leaf BGV \\
\hline Battery Type and Energy & Li-ion 24kWh \\
\hline All-electric range & $118 \mathrm{Km}$ \\
\hline $\begin{array}{l}\text { Charging/discharging } \\
\text { efficiency (Level } \\
\text { charging) }\end{array}$ & $92 \%$ \\
\hline Power rating & $4 \mathrm{~kW}$ \\
\hline
\end{tabular}

Proposed Framework for EV Load Sharing Among PV, BESS and Grid

This paper develops a system framework showing the electrical connection among the sources (PV, Battery and the grid) and the loads (EVs charging stations, AC loads and DC loads). Figure 1.1 clarifies basic requirement for the system proposed in this research. It consists of a grid tied PV with battery. The PV array is connected to the dc link via $\mathrm{dc} / \mathrm{dc}$ converter known as the dc booster in order to support the faster charging. BESS is used to deliver the part of peak load which significantly reduces the stress on the grid during peak time. Next, the battery energy storage system can supply 106 the electrical power to the DC-link through the boost converter. The grid electricity is also fed to the $\mathrm{DC}$-link via $\mathrm{AC} / \mathrm{DC}$ converter. This way the DC-link is fed with three sources.

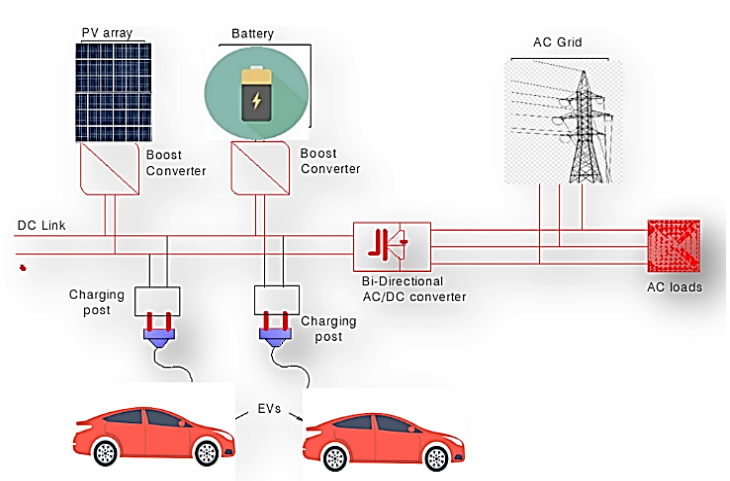

Figure III.I Proposed System Framework

A suitable power management technique has been proposed to prioritize the source of electrical power to the charging stations. First priority would be the PV source. Second priority would be the battery energy storage system. The major advantage of using battery energy storage system is that it can store electrical energy from the grid at the time of the day when the electricity tariff is low and supplies the load in the time when electricity tariff is high to reduce overall energy cost of the charging station. The charging posts are fed with electric power through the dc link. The number of charging posts in a station depends upon the capacity of the station.

\section{A. Electric Vehicle Charging}

Existing PEV charger hardware and technologies allow charging at either coordinated or uncoordinated manner. Uncoordinated charging strategy is used as it allows charging of EV at charger power rating continuously [11]. Once 
an EV is parked in charging station and is plugged in for charging, kwh demand of EV depends on its SOC level and is equivalent to following relation:

$$
\mathrm{E}_{\mathrm{ch}, \mathrm{i}}=\frac{\left(1-\mathrm{soc}_{\text {initial, } \mathrm{i}}\right) \mathrm{C}_{\mathrm{B}, \mathrm{i}}}{\eta}
$$

Where, $\mathrm{E}_{\mathrm{ch}, \mathrm{i}}$ is the charging kwh demand by the $\mathrm{EV}, \mathrm{SOC}_{\text {initial, } \mathrm{i}}$ is the state of charge at the time of arrival, $\mathrm{C}_{\mathrm{B}, \mathrm{i}}$ is the nominal battery capacity, and $\eta$ is on-board charger efficiency.

Total time taken for full charge of battery of EV after it is plugged in is estimated as:

$$
\mathrm{T}_{\mathrm{ch}, \mathrm{i}}=\frac{\mathrm{E}_{\mathrm{ch}, \mathrm{i}}}{\mathrm{P}_{\mathrm{i}, \text { rated }} \times \eta}
$$

Where, $\mathrm{P}_{\mathrm{i}, \text { rated }}$ is the rated power $(\mathrm{kW})$ of $\mathrm{i}^{\text {th }} \mathrm{EV}$.

\section{$B$. Load sharing in parallel connected}

\section{sources}

All change in the terminal voltage of the converters is carried out as per the load to be shared by their corresponding sources, and it's called droop regulation. Load sharing is modeled based on the interpolation of the droop characteristics as per the percentage load to be shared. Figure III.2 shows the droop characteristics of the PV when all the sources are on. It shows the variation of change in voltage as per the load to be shared. Based on the interpolation from the curve for the required sharing of load, the value of droop regulation is found out.

Figure III.II Variation of droop regulation of with \% load shared by PV when PV and Grid are $\mathrm{ON}$
When the converters are connected in parallel, they share load in accordance with their voltage output and overall resistance of the converter. when load is switched on/off suddenly, there is mismatch in converter output voltage because each converter tries to deliver the load. Which's why the circulating current will increase significantly, as each converter switch try to increase the share of current and this causes overloads in converters.

Fig. III.III shows a simplified diagram of two parallel connected converters. Output voltages, currents and resistances of the converter-1 and converter- 2 are represented by Vdc1 and $\mathrm{Vdc} 2$, I1 and $\mathrm{I}$, and $\mathrm{R} 1$ and $\mathrm{R} 2$ respectively. By applying Kirchhoff's Voltage law in converter circuits, following relations can be established[8].

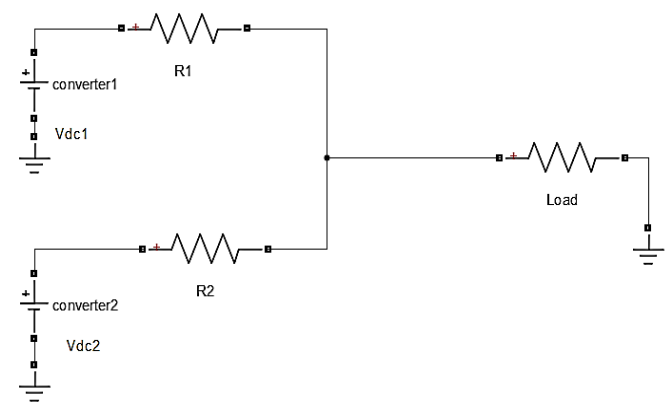

Figure IIII.III Two parallel connected converters $\mathrm{V}_{\mathrm{dc} 1}-\mathrm{I}_{1} \mathrm{R}_{1}-\mathrm{I}_{\mathrm{L}} \mathrm{R}_{\mathrm{L}}=0$

$\mathrm{V}_{\mathrm{dc} 2}-\mathrm{I}_{2} \mathrm{R}_{2}-\mathrm{I}_{\mathrm{L}} \mathrm{R}_{\mathrm{L}}=0$

Expressions for output currents from each converter can be derived from above equations as:

$I_{2}=\frac{\left(R_{1}+R_{L}\right) V_{d c 2}-R_{L} V_{d c 1}}{R_{1} R_{2}+R_{1} R_{L}+R_{2} R_{L}}$ 
$I_{2}=\frac{\left(R_{1}+R_{L}\right) V_{d c 2}-R_{L} V_{d c 1}}{R_{1} R_{2}+R_{1} R_{L}+R_{2} R_{L}}$

$\mathrm{I}=\mathrm{I}_{1}+\mathrm{I}_{2}$

The circulating current and overload load to the converter can be minimized by adding a droop regulation resistor Rdroop to each converter. By adding Rdroop1 and Rdroop2 in series with each converter, current sharing by individual converter can be improved. Droop resistor decreases the terminal voltage of each converter and minimizes the mismatch in current sharing.

Droop regulation is implemented by adding or subtracting value, equivalent to droop resistor voltage drop, from the reference voltage given to each converter's PID controller so that it could fix the output voltage of each converters in accordance with the percentage of load to be shared by them.

Value of reference voltage of each PID controllers is calculated as[12]:

$$
\begin{aligned}
& \mathrm{V}_{\text {ref } 2}=-\mathrm{m}_{2} \mathrm{P}_{2}+\mathrm{V}_{\mathrm{NL}} \\
& \mathrm{V}_{\text {ref } 2}=-\mathrm{m}_{2} \mathrm{P}_{2}+\mathrm{V}_{\mathrm{NL}}
\end{aligned}
$$

Where, $\mathrm{V}_{\mathrm{NL}}$ is the no load constant voltage, $\mathrm{m} 1$ and $\mathrm{m} 2$ are droop regulations obtained from slope of the voltage vs power plot. Value of $\mathrm{m} 1$ and $\mathrm{m} 2$ are calculated continuously as per the change in load demand by using interpolation method in which slope of droop characteristics is calculated according to the load to be shared. Here, $\mathrm{m}_{1} \mathrm{P}_{1}$ and $\mathrm{m} 2 \mathrm{P} 2$ is the value of voltages to be changed ( $\Delta \mathrm{V} 1$ and $\Delta \mathrm{V} 2)$. Value of $\Delta \mathrm{V} 1$ and $\Delta \mathrm{V} 2$ are formulated from the characteristics of $\%$ load vs $\Delta \mathrm{V}$.

C. Power Flow management algorithm 
load with Grid. By following the algorithm, continuous power availability for uncoordinated charging of EVs is implemented.

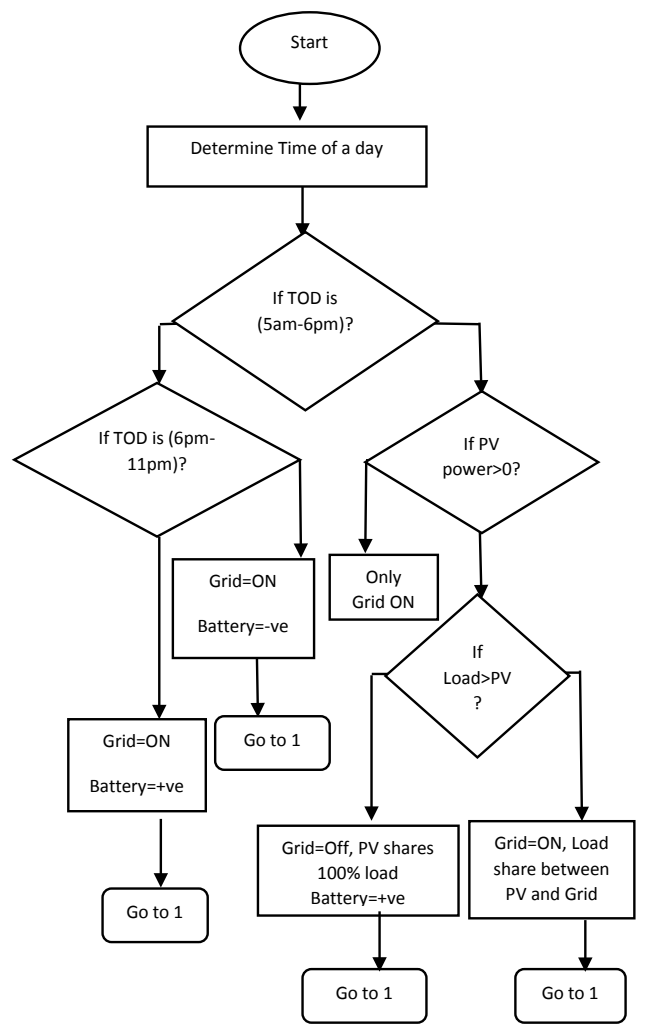

Figure IIII.IV Flow chart of Power management algorithm

\section{Results and discussions}

The proposed topology is simulated in MATLAB. EV load profile at different times of days is the key point for the selection of sources for the supply of their demand. The algorithm modeled in MATLAB determines the sources to be made on at certain time. Figure IV.I shows the estimation of load demanded by EVs at a particular day. The peak demand of EV is assumed to be $54 \mathrm{KW}$ from 7:00 pm to 9:00 pm in a typical day. The base load is assumed to be $28 \mathrm{KW}$. So, the rating of PV and BESS is chosen
$28 \mathrm{KW}$ each.

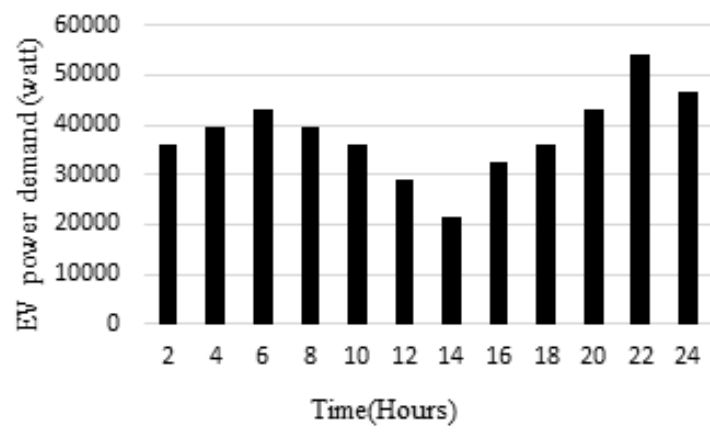

Figure IV.I estimated power demand by EVs in a typical day

Figure IV.II represents the variation of power generation from PV over the day based on temperature and irradiance data. It shows that $\mathrm{PV}$ generates maximum power of $28 \mathrm{~kW}$ during the mid-day which is equal to the base load required to be supplied. In other time there is no power generation from $\mathrm{PV}$.

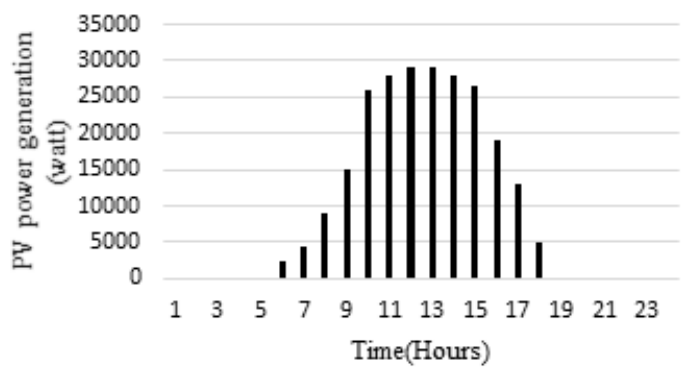

Figure IV.II PV power generation during a typical day

Figure IV.III (b) illustrates the load shared by PV for charging of EV during a typical day. It shows that when solar energy is available during the day time, then most part of the load is shared by PV. PV delivers all its power generation for charging of EVs as well as BESS is charged with excess power of PV. Energy from PV is not available during night time and it produces 


\section{Nepal Engineers' Association, Gandaki}

its maximum rated power only few hours a day as illustrated above. In the time when PV power is not sufficient to provide the load demand, Grid combines with the PV and shares the load with PV as shown in Figure IV.III(d). It shows that Grid power input is maximum during midnight time when the electricity tariff is low. On the other

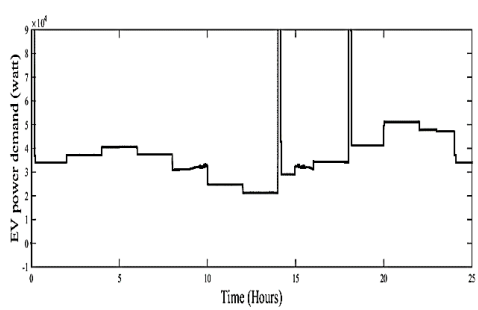

(a)

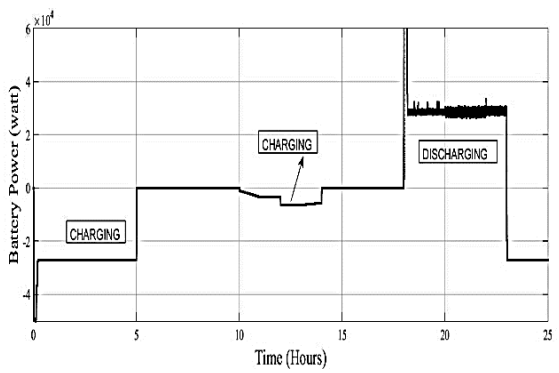

(c)

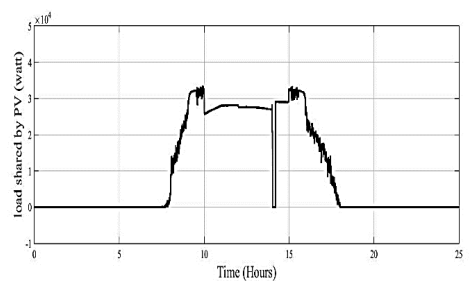

(b)

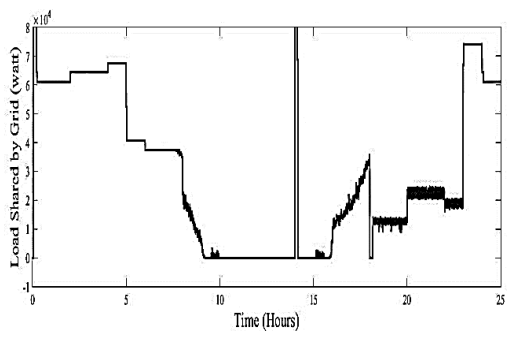

(d)

Figure IV.III Load shared by PV, BESS and Grid in watt. (a) actual power consumed by EV load. (b) Load shared by PV (c)load of charging and discharging of BESS and (d)Load shared by Grid hand, Grid power input is significantly small during peak load demand time and very small during day time when PV power is available. Figure IV.III(c) represents the load profile of BESS, which illustrates the charging and discharging power profile of energy storage system. It illustrates that the BESS is charged during the off-peak time when tariff rate is significantly lower (between $11 \mathrm{pm}-5 \mathrm{am}$ ). Charging can also be performed from PV power in the day time when the load power is less than PV power. It is discharged during peak hours from $6: 00 \mathrm{pm}$ to $11: 00 \mathrm{pm}$ in order to reduce the stress on the grid. During the peak hours, BESS is given more priority to supply the load, i.e. base load $28 \mathrm{KW}$ is supplied by battery and remaining load is supplied by the Grid. In the figure, positive BESS power represents the discharging of BESS, whereas negative power indicates the charging of battery.

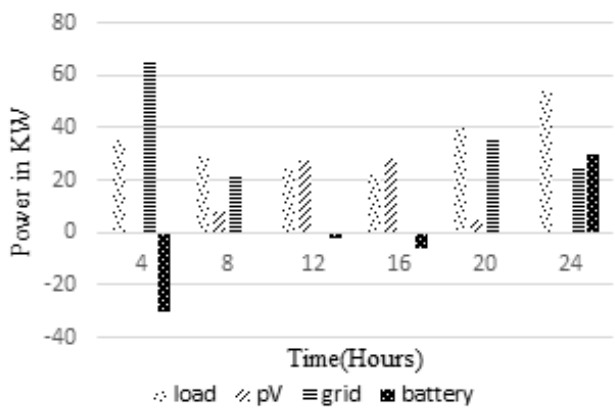

Figure IV.IV Load profiles of EVs, PV, BESS and Grid 
Figure IV.IV shows the load profiles of sources. It shows in the very morning; Grid power supply is greater than EV demand. This indicates extra power from the grid is used to charge BESS. Here, negative power indicates charging of battery. Likewise, in the mid-day, Grid power is very small or zero due to high power contribution by PV. In the peak load demand, BESS shares significant loads and hence reduces the stress in the grid. The simulation results clarify that EV load demands are fulfilled by prioritizing the sources on the basis of power management algorithm.

\section{Conclusions}

Proposed power flow management techniques for charging of electric vehicle has been presented in this paper. The objective of the proposed technique is to design a topology which supports fast charging of electric vehicles by the penetration of PV, and BESS into the grid, which significantly reduces the stress in the grid due to fast charging. The proposed idea is implemented by modeling EV loads profiles and prioritizing the sources accordingly in order to fulfill all the power demand of the EV loads. This supports uncoordinated method of charging of electric vehicles. Application of droop regulation method is implemented for the effective load sharing by different sources. The whole system is simulated in MATLAB and verified the effectiveness of the system under various load conditions. This work focuses on the penetration of renewable energy sources onto the grid for EV charging. This can reduce the effects on the electricity grids, which is caused by high power consumption for fast charging of EVs.

Technical Journal -2019

\section{References}

[1] A. Aslani, "Strategic variables of commercialization of renewable energy technologies," J. Renew. Sustain. Energy, 2015.

[2] N. Erdoğan, F. Erden, and T. Altun, "Coordinated Electric Vehicle Charging Strategy in Microgrids Containing PV System," vol. 4, no. 1, pp. 9-21, 2017.

[3] J. García-Villalobos, I. Zamora, J. I. San Martín, F. J. Asensio, and V. Aperribay, "Plug-in electric vehicles in electric distribution networks: A review of smart charging approaches," Renew. Sustain. Energy Rev., vol. 38, pp. 717-731, 2014.

[4] M. O. Badawy and Y. Sozer, "Power Flow Management of a Grid Tied PV-Battery System for Electric Vehicles Charging," IEEE Trans. Ind. Appl., vol. 53, no. 2, pp. 1347-1357, 2017.

[5] A. Ul-Haq, M. Azhar, Y. Mahmoud, A. Perwaiz, and E. A. Al-Ammar, "Probabilistic modeling of electric vehicle charging pattern associated with residential load for voltage unbalance assessment," Energies, vol. 10, no. 9, pp. 1-18, 2017.

[6] C. Balakishan, N. Sandeep, and M. V Aware, "Design and Implementation of Three-Level DC-DC Converter with Golden Section Search Based MPPT for the Photovoltaic Applications Design and Implementation of Three-Level DC-DC Converter with Golden Section Search Based MPPT for the Photovoltaic Applicatio," no. March 2015, 2016. 
[7] A. Hassoune, M. Khafallah, A. Mesbahi, and T. Bouragba, "Power management strategies of electric vehicle charging station based grid tied PV-battery system," Int. J. Renew. Energy Res., vol. 8, no. 2, pp. 851-860, 2018.

[8] P. Chaudhari, M. Khadse, V. Jadhav, P. Patil, and K. Daware, "Novel Control Strategy for Dynamic Load Sharing Between DC-DC Converters for DC Microgrid," vol. 2, no. 6, pp. 3-7, 2015.

[9] W. Kuihua, N. Xinsheng, W. Jian, W. Kuizhong, and J. Shanjie, "Electric Vehicle Load Characteristic Analysis and Impact of Regional Power Grid,” pp. 257-261, 2012.
[10] M. Karki and J. G. Singh, "An Approach to Enhance Battery Life of Gridable Vehicles and the Transformer Life in an Active Distribution System Using PSO," no. April 2017.

[11] K. Zhang et al., "Optimal Charging Schemes for Electric Vehicles in Smart Grid: A Contract Theoretic Approach," IEEE Trans. Intell. Transp. Syst., vol. 19, no. 9, pp. 3046-3058, 2018.

[12] R. M. Thomas and D. Jose, "Control Method for Parallel DC- DC Converters used in Standalone Photovoltaic Power System." 